\title{
A IMPERATIVIDADE DO NON-REFOULEMENT E A RECONSTRUÇÃO DO CONCEITO DE CIDADANIA
}

\section{THE IMPORTANCE OF NON-REFOULEMENT AND THE RECONSTRUCTION OF THE CONCEPT OF CITIZENSHIP}

\author{
Parcelli Dionizio Moreira* \\ Ana Beatriz Garcia ${ }^{* *}$
}

\section{RESUMO}

A situação dos refugiados no mundo hoje desafia as estruturas da governança global como jamais se viu. Uma das armas para enfrentar essa questão mundial é o chamado princípio do non-refoulement, instituto que possui suas raízes atreladas às do próprio conceito de Estado e que, com a reformulação do conceito de soberania e de cidadania, sofre também as implicações que dela decorrem. O que nos interessa analisar neste artigo é de que forma se constrói, hoje, o instituto do non-refoulement sobre uma base de norma com status de jus cogens. Para isso, a investigação foca na multidisciplinariedade dos conceitos existentes na doutrina do Direito Internacional dos Direitos Humanos, objetivando apresentar uma nova compreensão do direito dos refugiados, a partir de uma análise geral da normativa referente ao refúgio nos dias atuais e de uma abordagem universalista e multicultural da cidadania, distanciando-se da ideia de Estado-nação.

Palavras-chave: Direito Internacional dos Direitos Humanos. Refúgio. Nonrefoulement. Cidadania pós-nacional.

\begin{abstract}
The situation of refugees in the world today challenges the structures of global governance as never before. One of the tools used to face this global issue is the so-called non-refoulement principle, an institute that has its roots tied to the very concept of state that suffers the implications of the reformulation of the concept of sovereignty and citizenship. This article aims to analyze how the nonrefoulement principle is constructed nowadays with a jus cogens status standard base. To this end, the research focuses on multidisciplinary concepts present in the doctrine of International Human Rights Law with the aim of presenting a new understanding of refugee rights. This is done from an overview of the current rules concerning refugees and a general analysis of the current norms about refugees and a universalist and multicultural approach of citizenship, moving away from the nation-state idea.
\end{abstract}

Keywords: Human Rights International Law. Refuge. Non-refoulement. Postnational citizenship.

\footnotetext{
"Procuradoria-Geral da Fazenda Nacional. Mestrando em Direitos Fundamentais e Democracia pelo Centro Universitário Autônomo - UNIBRASIL de Curitiba/PR. Graduação em Direito pela Universidade Estadual de Londrina (2000).

${ }^{* *}$ Mestre em Estudos Internacionais pela Universidade de Santiago de Compostela (Espanha). Especialista em Direito Constitucional pela PUC - Pontifícia Universidade Católica de São Paulo.
} 


\section{Introdução}

O fenômeno das migrações forçadas se confunde com a própria história da humanidade. A situação atual dos refugiados no mundo, todavia, desafia as estruturas dos governos global como jamais se viu.

Uma das armas para enfrentar essa questão mundial é o chamado princípio do non-refoulement. Definido no artigo 33 da Convenção sobre o Estatuto dos Refugiados, assinada em Genebra, Suíça, em 1951, que surge para abarcar situações específicas, começa a se consolidar no período entre guerras, vinculado a ideia da discricionariedade estatal na concessão do refúgio. Assim, o instituto tem suas raízes atreladas às do próprio conceito de Estado e, portanto, com a reformulação do conceito de soberania e a superação do ideário da onipotência daquele, suplantado pelo direito das gentes e pelo foco no indivíduo, sofre as implicações que dela decorrem.

O papel que assume o direito internacional dos direitos humanos é, de certa forma, um fenômeno recente, tendo como eixo fundamental o princípio da dignidade da pessoa humana e os direitos humanos reconhecidos em atos internacionais celebrados pelo Estado, e que tem influenciado, inclusive, a doutrina pátria, outrora apegada a um racionalismo positivista puro, com enfoque no direito interno, incapaz de refletir acerca da relevância dos princípios na busca de uma ordem jurídica justa. Essa influência, a nível mundial, se reflete, destarte, na maneira como hoje se encara o non-refoulement.

Assim, o que nos interessa analisar neste artigo é de que forma se constrói hoje no instituto do non-refoulement sobre uma base de norma com status de jus cogens - imperativa, consuetudinária, que não pode ser derrogada, com natureza peremptória - a vincular os Estados no trato com os indivíduos em busca de abrigo e como o princípio se torna, nesse sentido, uma das maiores garantias a salvaguardar o ser humano.

Para tanto, a pesquisa documento realizada neste artigo centrou-se numa abordagem mais ampla, trazendo uma análise geral da normativa referente ao refúgio nos dias atuais, bem como de dados estatísticos sobre o refúgio no Brasil, apresentando o princípio do non-refoulement vinculado a este contexto.

A primeira parte encerra-se na cristalização de sua estrutura como norma de jus cogens, a partir da multidisciplinariedade dos conceitos no Direito Internacional dos Direitos Humanos.

Em seguida, apresenta-se um panorama a respeito do instituto no Brasil na atualidade e de que forma o país passou à posição de referência no abrigo de refugiados.

Por fim, tendo em vista o longo caminho que ainda se faz necessário percorrer na seara da proteção dos refugiados, o artigo traz uma reflexão a respeito do próprio conceito de cidadania em um contexto de mundo pós-globalizado, a fim de indicar soluções para este sistema de governança global em transição.

\section{0 regime internacional de proteção dos refugiados nos dias atuais}

A configuração atual do sistema de proteção dos refugiados no mundo surge no contexto da Segunda Guerra Mundial, quando o problema dos refugiados tomou proporções jamais vistas. Desde os acordos de Westfália, em 1648, ainda que de forma incipiente, passou-se a constatar um sistema de proteção internacional de refugiados em paralelo ao sistema de Estados modernos de então. Após a Primeira Guerra Mundial, respondendo ao histórico de perseguições do período, um regime mais abrangente começou a emergir. Entretanto, foi apenas com as negociações internacionais decorrentes da Segunda Guerra que o regime contemporâneo se consolidou.

Em 28 de julho de 1951, três anos após a adoção da Declaração Universal dos Direitos Humanos, a Conferência das Nações Unidas de Plenipotenciários sobre o Estatuto dos Refugiados e Apátridas aprova a Convenção sobre o Estatuto dos Refugiados. Tal Conferência, realizada em Genebra entre os dias 2 e 25 de julho de 1951, tinha como objetivo completar a minuta da Convenção e assiná-la (MOREIRA, 2007). Duas correntes de pensamento distintas marcaram a Conferência: uma entendia que a Convenção consistia num instrumento geral, que deveria ser aplicável a todos os refugiados, independentemente de sua origem; outra que a Convenção tinha seu alcance limitado e deveria se aplicar somente aos refugiados originários de países europeus. Uma das justificativas utilizadas por esses países consistia no fato de que já acolhiam um grande número de refugiados e, caso a definição fosse muito ampla, não teriam condições financeiras de abrigar um contingente maior deles. 
Diante disso, somente poderiam se comprometer com as obrigações contidas na Convenção se esta adotasse uma definição limitada de refugiado. Outro argumento levantado se fundava no fato de que os refugiados existentes no mundo (naquela época) tinham origem europeia e que, portanto, tratava-se de um problema europeu. $\mathrm{Na}$ décima nona reunião da Conferência, o representante da França afirmou que, caso não fosse adotada uma definição limitada, aplicável somente à Europa, não assinaria a Convenção. Em face disso, na reunião seguinte, o representante da Suíça propôs uma emenda ao artigo $1^{\circ}$, possibilitando a realização de reservas a esse dispositivo. $\mathrm{Na}$ vigésima terceira reunião, o representante do Vaticano propôs que os dois pontos de vista fossem conciliados no texto do artigo $1^{\circ}$, evitando a possibilidade de reservas. Com isso, a definição poderia ser aplicável somente aos refugiados europeus ou aos de todos os continentes. Caberia ao Estado contratante adotar a fórmula que julgasse adequada quando da assinatura, adesão ou ratificação do instrumento. Assim, estabeleceu-se uma definição geral do termo "refugiado".

Uma interpretação histórica do instrumento base da proteção dos refugiados no mundo - a Convenção de Genebra de 1951 sobre Estatuto dos Refugiados - deixa evidente, portanto, que a intenção dos países que acorreram ao instrumento internacional, reunidos na cidade suíça por decisão da Assembleia Geral das Nações Unidas de 1950', era apenas uma: a de solu-

\footnotetext{
${ }^{1}$ La presente Convención se firmo el 28 de julio de 1951, en aplicación de la Resolución 429 (V) de la Asamblea General, de 14 de diciembre de 1950, entrando en vigor el 22 de abril de 1954, con el depósito del $6^{\circ}$ instrumento de ratificación. Sus orígenes se hallan enmarcados en el periodo 1947-1950, bastante fructífero en lo que se refiere a la puesta en marcha del sistema institucional de las Naciones Unidas. El ECOSOC - Consejo Económico y Social, tras un informe de la Comisión de Derechos Humanos en su Resolución 116 (VI) D de 1 y 2 de marzo de 1948, había invitado al Secretario General a estudiar la cuestión de los apátridas y la posibilidad de adoptar una nueva convención sobre el asunto (en este entonces, los Convenios sobre refugiados son los de 1933 y 1938 - este último completado por un Protocolo adicional de 1939 -, los cuales se aplicaban a grupos determinados de refugiados, por lo que no incluía a las nuevas categorías que surgían). De ahí surge Un estudio sobre la apatridia, documento clave para la obra de las Naciones Unidas sobre refugiados, que concluye por la necesidad de un nuevo Convenio de carácter universal. Por la Resolución 248 (IX) B de 8 agosto de 1949, el ECOSOC nombra un Comité especial para los refugiados y apátridas, compuesto por representantes de 13 gobiernos, con el fin de elaborar tal convenio. La Resolución 319 (XI) B de 16 de agosto de 1950 pide al Comité revisar el texto y someter a la Asamblea General un proyecto de preámbulo y definición del término refugiado. El mismo día que se aprueba el estatuto del Alto Comisionado de las Naciones Unidas para los Refugiados - Acnur, adopta la Resolución 429 (V) sobre el Proyecto del Convenio, para el que se convoca en Ginebra una Conferencia de Plenipotenciarios, a la cual acuden, del 2 al 25 de julio de 1951, 17 Estados europeos, 6 americanos, 4 asiáticos y 1 por Oceanía. Son ellos: Australia, Austria, Bélgica, Brasil, Canadá, Colombia, Dinamarca, Egipto, Estados Unidos, Francia, Grecia,
}

cionar um problema pontual e premente, decorrente das duas então recentes grandes guerras que assolaram o continente europeu. Naquele momento, embora a migração já fosse uma questão há muito incômoda, era inexorável encontrar uma solução para os milhares de expatriados provenientes dos conflitos.

É neste sentido o conceito plasmado no art. $1^{\mathrm{o}}$, A, 2, da Convenção, que considera refugiado aquele:

2) Que, em consequência dos acontecimentos ocorridos antes de $1^{\circ}$ de janeiro de 1951 e temendo ser perseguida por motivos de raça, religião, nacionalidade, grupo social ou opiniões políticas, se encontra fora do país de sua nacionalidade e que não pode ou, em virtude desse temor, não quer valer-se da proteção desse país, ou que, se não tem nacionalidade e se encontra fora do país no qual tinha sua residência habitual em consequência de tais acontecimentos, não pode ou, devido ao referido temor, não quer voltar a ele .

Portanto, quando se elaborou o que viria a ser a Carta Magna do Direito dos Internacional dos Refugiados no mundo, pensou-se em uma definição que abarcava um temor fundado de perseguição por razões de raça, religião, nacionalidade, grupo social ou opiniões políticas. Não omitiram deliberadamente questões de gênero (KUMIN, 2001, p. 12), ambientais ou econômicas, por exemplo; simplesmente não pensaram nelas. Hoje, elas voltam a assombrar o mundo.

A limitação do conceito de refugiado da Convenção de 1951 é epicentro, nos dias hodiernos, de uma questão a nível mundial. Segundo dados do Acnur (Agência para Refugiados da ONU), o número de refugiados é o maior desde a Segunda Guerra (FOULKES, 2015). Os números são apenas reflexos de um sistema que há muito não consegue dar conta de resolver os problemas dos refugiados e implica na necessária revisão de suas bases conceituais.

Ao mesmo tempo em que são cada vez maiores os influxos de pessoas em busca de refúgio, são também cada vez mais presentes as medidas e controles restritivos empregados pelos países para os quais eles se dirigem (especialmente, mas não exclusivamente, países desenvolvidos).

\footnotetext{
Vaticano, Irak, Israel, Italia, Luxemburgo, Mónaco, Noruega, Países Bajos, Reino Unido, República Federal Alemana, Suecia, Suiza, Turquía, Venezuela y Yugoslavia (con observadores de Cuba e Irán). Súmanse a ellos, dos organismos especializados de las Naciones Unidas, OIT y OIR, y 29 ONGs, consolidando lo que tenemos hoy como la "Carta Magna" en materia de refugiados (ARENAS HIDALGO, 2005, p. 75).
} 
E é nesta seara que entra a discussão a respeito da natureza jurídica que hoje assume o "princípio do non refoulement".

\section{0 princípio do non-refoulement e a nova configuração do Estado}

Em sua essência, o non-refoulement "é o princípio de que um Estado não deve obrigar uma pessoa a retornar a um território onde possa estar exposta à perseguição" (PAULA, 2015, p. 51-52). Se por um lado o Estado possui o direito de não abrigar o refugiado, possui, de outra banda, a obrigação de zelar pela vida e segurança dele, o que se sobrepõe; assim, se não for possível encontrar outro Estado que o acolha, sua única opção será recebê-lo (GUIMARÃES, 2014, p. 21). Segundo o art. 33 da já citada Convenção para o Estatuto dos Refugiados (1951):

Art. 33. Proibição de expulsão ou de rechaço 1. Nenhum dos Estados Contratantes expulsará ou rechaçará, de maneira alguma, um refugiado para as fronteiras dos territórios em que a sua vida 16 ou a sua liberdade seja ameaçada em virtude da sua raça, da sua religião, da sua nacionalidade, do grupo social a que pertence ou das suas opiniões políticas. 2 . O benefício da presente disposição não poderá, todavia, ser invocado por um refugiado que por motivos sérios seja considerado um perigo para a segurança do país no qual ele se encontre ou que, tendo sido condenado definitivamente por crime ou delito particularmente grave, constitui ameaça para a comunidade do referido país.

Nesse passo, o non-refoulement é componente essencial da proteção internacional dos refugiados, princípio pelo qual se reforça o dever de um Estado de não devolver pessoas a determinados locais e em determinadas circunstâncias, ideia relativamente recente na história da humanidade (GUIMARÃES, 2014, p. 53), à medida que, em passado não muito distante, eram comuns os acordos entre Estados para a entrega recíproca de subversivos, dissidentes, traidores e afins.

E esse giro completo na natureza da não devolução deriva de uma alteração ainda mais profunda, que provém das bases do direito internacional e possui implicações na própria estrutura do conceito de Estado. Se em passado não muito distante o Estado era o sujeito por excelência, dotado de todo o poder que se poderia conceber, era direito seu decidir a quem concederia o beneplácito de se estabelecer em seu território e viver em meio a sua gente. Hoje, com os conceitos de soberania e nacionalidade sendo revisitados, mormente à luz do hodierno direito das gentes, não se concebe mais que um Estado, sob o argumento da absoluta soberania, descumpra tratados e convenções internacionais que impõem normas de ordem pública de observância obrigatória pelos signatários desses acordos.

\section{O princípio do non-refoulement como norma de jus cogens}

Em meados do século XIX, os deslocamentos em massa, resultantes dos massacres de minorias na Rússia e no Império Otomano, e as perturbações políticas na Europa e América do Sul, acabaram por consolidar o ideário de que, muitas vezes, aqueles que fugiam de seu próprio governo, mereciam guarida e proteção (GOODWIN-GILL, 1998, p. 117-118).

Em 1928 foi adotado o Ajuste Relativo ao Estatuto Jurídico dos Refugiados Russos e Armênios, cujo item 7 pode ser considerado um embrião do princípio do non-refoulement em instrumentos internacionais; em 1933 foi adotada a Convenção Relativa ao Estatuto Internacional dos Refugiados, a primeira convenção internacional a estabelecer, em seu art. $3^{\circ}$, o princípio do non-refoulement; em 1936 foi adotado o Ajuste Provisório Relativo ao Estatuto dos Refugiados Provenientes da Alemanha e em 1938 Convenção Relativa ao Estatuto dos Refugiados Provenientes da Alemanha, ambos contendo limitações à extradição e ao retorno.

As primeiras referências ao instituto, portanto, surgiram na prática internacional do período entre guerras. O direcionamento a grupos específicos, entretanto, impediu a consolidação de um princípio do non-refoulement formal. Com o fim da Segunda Guerra Mundial, ele acaba por se configurar como "princípio básico e pedra angular do Direito Internacional dos Refugiados" (PAULA, 2015, p. 54).

Mas hodiernamente, a discussão em torno desse instituto baseia-se em definir se podemos qualificar sua natureza como norma imperativa de direito internacional, com status de jus cogens, levando em consideração a proteção que confere ao núcleo mais básico dos direitos humanos, com foco no indivíduo. 
Para iniciar o debate é necessário partir da premissa de que o ideário do non-refoulement tem sentido amplo, sendo utilizado em outros contextos dentro dos direitos humanos. E embora o foco do presente artigo seja tratar do princípio dentro do âmbito do direito dos refugiados, não se pode olvidar que os institutos nesta seara são complementares e utilizados, sobretudo, quando o indivíduo deslocado acaba por não se encaixar na definição limitada ${ }^{2}$ da Convenção de Genebra de 1951. Como dito anteriormente, a Convenção reflete o contexto em que foi redigida, o que resulta na incapacidade de abarcar os novos desafios que emergem no mundo contemporâneo.

É nesse sentido que a Convenção da Organização da Unidade Africana (OUA) que rege os aspectos específicos dos problemas dos refugiados na África, datada de $1969^{3}$, e a Declaração de Cartagena sobre os Refugiados, de 1984', trouxeram definições mais abrangentes do termo, que, além da definição da Convenção de Genebra de 1951 e do Protocolo de 1967, englobam, entre outros, perturbações à ordem pública e violações maciças dos direitos humanos como causas para o refúgio.

Em âmbito europeu, o artigo 19 da Carta de Direitos Humanos da União Europeia (CDFUE), que cristaliza o princípio do non-refoulement, é considerado um direito autônomo por ter sido consagrado como princípio de Direito Internacional antes de sua normatização no instrumento citado. O non-refoulement é só a base sobre a qual se erige o artigo, já que suas implicações na Carta são mais extensas que as previstas no Direito Internacional geral. A segunda parte do artigo reformula o consagrado princípio clássico da

\footnotetext{
2 "However, the terminology used by the General Assembly has been far from consistent, ranging from 'refugees for whom the [High Commissioner] lends his good offices' to 'refugees and displaced persons' or 'victims of man-made disasters"” (MANDAL, 2005, p. 4).

${ }^{3}$ Cf. art. I, 2 da Convenção africana: "O termo refugiado aplica-se também a qualquer pessoa que, devido a uma agressão, ocupação externa, dominação estrangeira ou a acontecimentos que perturbem gravemente a ordem pública numa parte ou na totalidade do seu país de origem ou do país de que tem nacionalidade, seja obrigada a deixar o lugar da residência habitual para procurar refúgio noutro lugar fora do seu país de origem ou de nacionalidade".

${ }^{4}$ Cf. recomendação terceira da Declaração: "Deste modo, a definição ou o conceito de refugiado recomendável para sua utilização na região é o que, além de conter os elementos da Convenção de 1951 e do Protocolo de 1967, considere também como refugiados as pessoas que tenham fugido dos seus países porque a sua vida, segurança ou liberdade tenham sido ameaçadas pela violência generalizada, a agressão estrangeira, os conflitos internos, a violação maciça dos direitos humanos ou outras circunstâncias que tenham perturbado gravemente a ordem pública".
}

proibição de devolução ou expulsão, acrescentando a proibição de extradição e exigindo em todo caso o cumprimento de um requisito fundamental: a existência de um grave risco de ser submetido a tortura ou tratamentos desumanos e degradantes ou a pena de morte. Essa indicação específica diferencia a determinação do artigo da Carta de qualquer outra, uma vez que, em geral, os instrumentos limitam-se a vincular o non-refoulement com a existência de um perigo a vida, mas sem indicar especificamente que esse perigo possa vir de uma sanção institucionalizada prevista nos ordenamentos internos dos Estados (MARTÍNEZ, 2012, p. 432-433).

Ademais, o art. 19 é tido como norma complementar ao art. $4^{\circ}$ da Carta, que estabelece explicitamente a proibição à tortura e outros tratos desumanos e degradantes, razão pela qual se considera que o primeiro tem força suplementar derivada dessa conexão. A proibição da tortura é norma imperativa e consagrada de direito internacional ${ }^{5}$, o que, por sua vez, dota de força coercitiva o art. 19.

Nesse caminhar, a própria letra da Convenção contra a Tortura de 1984 prevê um leque de garantias às pessoas que temem tortura no seu país de origem ou em qualquer outro território para o qual elas possam ser enviadas, consideravelmente mais amplo do que a proteção garantida Convenção de Genebra de 1951. Por primeiro, diferentemente da Convenção para os Refugiados de 1951 na cláusula $1^{\text {a }}(\mathrm{F})$, inadmite qualquer cláusula ou previsão de exclusão. A proibição contra a tortura é absoluta e em circunstância nenhuma pode ser violada. Seu Comitê contra a Tortura decidiu, por diversas vezes, em casos de solicitantes de refúgio que tiveram o seu pedido de refúgio negado, que a devolução do peticionário ao seu país de origem ou, em alguns casos, a outro Estado, constituiria uma violação do art. $3^{\circ}$ da Convenção, visto que existia, nesses países risco de que os peticionários fossem submetidos à tortura ${ }^{6}$.

No contexto da América Latina, a Declaração de Cartagena, como ressaltado anteriormente, tem

\footnotetext{
${ }^{5}$ Nesse sentido, ver, em âmbito europeu, decisões do Tribunal Penal Internacional para a antiga Iugoslávia e do Tribunal Europeu de Direitos Humanos no assunto Al-Adsani vs. Reino Unido, entre outros.

${ }^{6}$ Destacam-se os casos Balabou Mutondo versus Suiça (1994),32 Tahir Hussain Khan versus Canadá (1994), Ismail Alan versus Suiça (1996), 34 Aemei versus Suécia (1996), Pauline Muzonzo Paku Kisoki versus Suécia (1996), Tapia Paez versus Suécia (1997), Korban versus Suécia (1998), Halil Haydin versus Suécia (1998) e Elmi versus Austrália (1999), cf. PAULA (2015, p. 55).
} 
uma definição mais abrangente do que a Convenção de Genebra de 1951, sobretudo ao prescrever que a ameaça pode ocorrer por outras circunstâncias que perturbem gravemente a ordem pública, o que amplia o campo de sua incidência (BIJOS, 2014, p. 109).

$\mathrm{O}$ princípio do non-refoulement vem expresso também na Convenção Americana dos Direitos Humanos (Pacto de San José da Costa Rica), que, em seu artigo 22, item 8, prevê que "em nenhum caso o estrangeiro pode ser expulso ou entregue a outro país, seja ou não de origem, onde seu direito à vida ou à liberdade pessoal esteja em risco de violação em virtude de sua raça, nacionalidade, religião, condição social ou de suas opiniões políticas" (PROCURADORIA, 1969).

Em solo brasileiro, sobreveio, em 1997, a Lei ${ }^{\circ}$ 9.474, que define mecanismos para a implementação do Estatuto dos Refugiados de 1951, reconhecendo como refugiado todo indivíduo que: a) devido a fundados temores de perseguição por motivos de raça, religião, nacionalidade, grupo social ou opiniões políticas encontre-se fora de seu país de nacionalidade e não possa ou não queira acolher-se à proteção de tal país; b) não tendo nacionalidade e estando fora do país onde antes teve sua residência habitual, não possa ou não queira regressar a ele, em função das circunstâncias descritas no inciso anterior; c) devido a grave e generalizada violação de direitos humanos, é obrigado a deixar seu país de nacionalidade para buscar refúgio em outro país (BRASIL, Lei n 9.474, 1997).

O princípio do non-refoulement também está inserido nas disposições da Lei $n^{\circ}$ 9.474/1997, a qual proíbe a deportação do estrangeiro que venha a pedir refúgio no Brasil (art. $7^{\circ}, \S 1^{\circ}$ ), bem como estabelece que o reconhecimento da condição de refugiado obstará o seguimento de qualquer pedido de extradição baseado nos fatos que fundamentaram a concessão de refúgio, prevendo ainda que a solicitação de refúgio suspenderá, até decisão definitiva, qualquer processo de extradição pendente, em fase administrativa ou judicial, baseado nos fatos que fundamentaram a concessão de refúgio (arts. 33 e 34) e, além disso, determina que não será expulso do território nacional o refugiado que esteja regularmente registrado, salvo por motivos de segurança nacional ou de ordem pública, caso em que sua retirada far-se-á para país diverso daquele onde sua vida, liberdade ou integri- dade física esteja em risco (arts. 36 e 37) (BRASIL, Lei $\mathrm{n}^{\circ}$ 9.474, 1997).

A lei brasileira abarca duas exceções à expulsão do refugiado do território nacional: a primeira fundamentada em motivos de segurança nacional e a segunda por razões de ordem pública, conceitos amplos e complexos, em que o intérprete deve se orientar pela ratio legis da Lei 9.474/97, qual seja, "a proteção da vida, da segurança e da liberdade do refugiado, orientada de maneira a prestar uma atividade eminentemente humanitária, sem o amargo tempero do interesse político" (LUZ FILHO, 2001, p. 202).

Essas exceções à proibição de rechaço no caso de expulsão estão em harmonia com o disposto no artigo 33 da Convenção de Genebra relativa ao Estatuto dos Refugiados, que prescreve em seu item 2 que o direito ao refúgio não poderá ser invocado por um refugiado que, por motivos sérios seja considerado um perigo para a segurança do país no qual ele se encontre ou que, tendo sido condenado definitivamente por crime ou delito particularmente grave, constitui ameaça para a comunidade do referido país (Acnur, 1951). Nesse sentido:

Similarly, the danger posed must be to the community of the country of refuge. This follows simply from the words of the clause. The issue is not whether the refugee poses a threat to some community elsewhere. Such a threat may be addressed through normal criminal or other procedures. It is only where the potential danger is to the community of the country of refuge that the exception will operate. (...)Equally, while the assessment of the danger to the community allows the State of refuge some margin of appreciation, there are limits to its discretion. Indeed, these are more specific than in the case of the national security exception. In particular, the operation of the danger to the community exception requires that the refugee must have been (a) convicted by a final judgment, (b) of a particularly serious crime (...) This requirement is not met simply by reason of the fact that the person concerned has been convicted of a particularly serious crime. An additional assessment is called for which will hinge on an appreciation of issues of fact such as the nature and circumstances of the particularly serious crime for which the individual was convicted, when the crime in question was committed, evidence of recidivism or likely recidivism, etc. Thus, it is unlikely that a conviction for a crime committed in the distant past, 
where there may have been important mitigatory circumstances, and where there is no evidence of recidivism could justify recourse to the exception (LAUTERPACHT, 2015, p. 138-140)7.

Dessa forma, a conjugação do conceito de refugiado, estabelecido pelos atos internacionais e também pela legislação interna, com as exceções à aplicação do princípio do non-refoulement, delimitam a atuação estatal, de modo que o Estado destinatário do pedido de refúgio não poderá negar abrigo ao indivíduo que não ofereça ameaça ao país para o qual se pede o refúgio, uma vez caracterizado que o direito à vida ou à liberdade pessoal, bem como sua integridade física, esteja em risco de violação em virtude de sua raça, nacionalidade, religião, condição social ou de suas opiniões políticas, ou ainda se essas ameaças resultarem de outras circunstâncias que perturbem gravemente a ordem pública no país de origem do solicitante.

Por outro lado, a aplicação dessas exceções pelo Estado para o qual se pede o refúgio pode acarretar conflitos com normas de direito internacional ou mesmo a violação dessas diretrizes, sobretudo na perspectiva dos direitos humanos, à medida que, à luz do que aqui se defende, já se reconhece, na doutrina do direito das gentes, o caráter de jus cogens do princípio do non-refoulement:

À luz do princípio da não devolução, ninguém pode ser obrigado a retornar a um país em que sua vida e liberdade estejam ameaçadas. Esse direito é consagrado no art. 33 da Convenção de 1951, quando afirma que "nenhum dos Estados-contratantes expulsará

\footnotetext{
7 Tradução livre: "Da mesma forma, o perigo deve se mostrar para a comunidade do país de refúgio. Isto se deduz simplesmente a partir das palavras da cláusula de exceção à aplicação do non-refoulement. A questão não é se o refugiado constitui uma ameaça para alguma comunidade em outro lugar. Tal ameaça pode ser identificada através de procedimentos penais ou outros procedimentos. Somente se o perigo potencial for dirigido à comunidade do país de refúgio é que a exceção irá operar. [...] Igualmente, enquanto a avaliação do perigo para a comunidade permite que o Estado de refúgio tenha certa margem de apreciação, há limites para o exercício do poder discricionário do Estado que recebe o solicitante. Com efeito, estes são mais específicos do que no caso de a exceção de segurança nacional. Em particular, o fundamento do perigo à comunidade para se constituir numa exceção exige que o refugiado deve ter sido (a) condenado por sentença final, (b) por um crime particularmente grave [...] Uma avaliação adicional dependerá de uma apreciação da matéria de facto, tais como a natureza e as circunstâncias do crime particularmente grave ao qual o indivíduo foi condenado, quando o crime em questão foi cometido, a prova de reincidência ou provável reincidência, etc . Assim, é pouco provável que uma condenação por um crime cometido em passado distante, em que pode ter havido circunstâncias mitigadoras importantes, e em que não há nenhuma evidência de reincidência possa justificar o recurso à exceção".
}

ou repelirá um refugiado, seja de que maneira for, para as fronteiras dos territórios onde a sua vida ou a sua liberdade sejam ameaçadas em virtude de sua raça, religião, nacionalidade, filiação em certo grupo social ou opiniões políticas. O princípio do non-refoulement é, assim, um princípio geral tanto do Direito dos Refugiados como do Direito dos Direitos Humanos, devendo ser reconhecido como um princípio de jus cogens (PIOVESAN, 2013, pp. 236-237).

A Convenção relativa ao Estatuto dos Refugiados, inclusive, não permite reservas dos Estados signatários do referido tratado no que diz respeito ao artigo 33, o qual versa exatamente sobre a proibição de devolver o solicitante de refúgio ao território onde exista ameaça a sua vida, a sua liberdade ou a sua integridade física, o que corrobora a ideia de que o princípio do non-refoulement tem o caráter de norma de jus cogens:

Non-refoulement, as a jus cogens norm, permits no derogation. This is in keeping with Article 42 of the 1951 Convention, which forbids state parties from making reservations to the Convention's non-refoulement provisions. The rationale for prohibiting derogation from a jus cogens norm is clear: It prevents states from treating objectively illegal behavior as legal, thereby excluding the possibility that jus cogens norms will be violated, fragmented, or subject to regional adaptation (FARMER, 2008, p. $29-30){ }^{8}$

Essa norma de jus cogens, que é imperativa e limita as ações e interações dos Estados, não tem uma definição precisa; todavia pode-se afirmar que, como no caso do princípio do non-refoulement, versa sobre algo que não pode ser ignorado, cuja observância é imperiosa pelos Estados convenentes:

[...] O termo imperativo não equivale a obrigatório, característica intrínseca às normas jurídicas, mas é uma obrigatoriedade mais elevada, mais constringente. O mais importante resulta também do fato de que as normas seriam imperativas em razão de seu conteúdo mais relevante, mais essencial.

\footnotetext{
${ }^{8}$ Tradução livre: "Non-refoulement como norma de jus cogens, não admite derrogação. Isto está em consonância com o artigo 42 da Convenção de 1951, que proíbe os Estados-parte de fazer reservas às disposições da Convenção que versam sobre o non-refoulement. A lógica em proibir a derrogação de uma norma de jus cogens é evidente: proibir os Estados de tratar objetivamente um comportamento ilegal como se legal fosse, excluindo, assim, a possibilidade de uma norma de jus cogens vir a ser violada, fragmentada ou submetida a adaptações locais".
} 
Essa única certeza acerca do jus cogens, o seu plus de importância, é a característica singular que evidencia o problema do seu lugar relativo no direito internacional e da capacidade da teoria geral desse direito de explicar o fenômeno de modo satisfatório: a ideia de jus cogens introduz de modo inevitável algum tipo de hierarquia normativa numa ordem jurídica que até ali a dispensava (NASSER, 2005, pp. 161-178).

O Artigo 53 da Convenção de Viena sobre Direito dos Tratados de 1969, estabelece:

Para os fins da presente Convenção, uma norma imperativa de Direito Internacional geral é uma norma aceita e reconhecida pela comunidade internacional dos Estados como um todo, como norma da qual nenhuma derrogação é permitida e que só pode ser modificada por norma ulterior de Direito Internacional geral da mesma natureza (BRASIL, Decreto $n^{\circ} 7.030,2009$ ).

Portanto, para se determinar se o princípio do non-refoulement atingiu o valor normativo de jus cogens é necessário que dois requisitos sejam preenchidos: (a) o reconhecimento pela comunidade internacional dos Estados como um todo e (b) o reconhecimento como norma da qual nenhuma derrogação é permitida.

Quanto ao primeiro requisito, de clareza solar, que o princípio do non-refoulement é amplamente aceito como regra geral de direito costumeiro, conforme amplamente demonstrado ao longo do texto. Seu caráter de criação normativa, o apoio representativo, inclusive e sobretudo por parte daqueles Estados mais afetados, e a prática consistente, corroboram esta posição9.

No que se refere à não-derrogabilidade do princípio, esse caráter é reafirmado, insistentemente, por vários instrumentos internacionais, como o já apontado acima artigo 42 (1) da Convenção de Genebra de 1951, pelo artigo $7^{\circ}$ (1) do Protocolo de 1967, que impedem reservas ao artigo 33 da Convenção de 1951 , bem como pelo artigo $3^{\circ}$ da Convenção contra a Tortura de 1984, de acordo com as afirmações do Comitê contra a Tortura, pelo artigo $4^{\circ}$ (2) do Pacto Internacional de Direitos Civis e Políticos e o Comitê de Direitos Humanos das Nações Unidas, que não permitem derrogação do artigo $7^{\circ}$ do Pacto. A Resolução

\footnotetext{
${ }_{9}^{9}$ Para maior digressão a respeito dos requisitos neste ponto, ver PAULA,
} 2015, p. $59-62$.
52/132 de 12 de dezembro de 1997 da Assembleia Geral das Nações Unidas afirma que "the principle of non-refoulement is not subject to derogation" (PAULA, 2015, p. 63).

No âmbito americano, a quinta conclusão a respeito da Declaração de Cartagena de 1984 reitera a importância do princípio do non-refoulement, incluindo a proibição de rejeição nas fronteiras, "como pedra angular da proteção internacional dos refugiados", estabelecendo que "este princípio imperativo respeitante aos refugiados, deve reconhecer-se e respeitar-se no estado atual do direito internacional, como um princípio de jus cogens". A Declaração de San José sobre os Refugiados e Pessoas Deslocadas de 1994 e a Declaração e Plano de Ação do México para Fortalecer a Proteção Internacional dos Refugiados na América Latina de 2004, também reafirmaram a natureza jus cogens do princípio do non-refoulement (PAULA, 2015, p. 63).

$\mathrm{Na}$ Europa, como visto acima nas digressões a respeito do artigo 19 Carta de Direitos Humanos da União Europeia (CDFUE) (também na jurisprudência do artigo $3^{\circ}$ da Convenção Europeia de Direitos Humanos), o non-refoulement é interpretado de modo incondicional.

Por fim, necessário salientar que no âmbito interno dos próprios Estados, como visto no que se refere à legislação brasileira ${ }^{10}$, se reconhece o caráter peremptório do non-refoulement.

Está em pleno desenvolvimento um processo de transição do direito internacional Westfaliano para um novo "direito cosmopolita", ao qual corresponde a dimensão social e comunicativa da cidadania (ZOLO, 2005, p. 49-66), a qual projeta a superação da vinculação entre cidadania e o velho conceito de Estado-nação.

Nesse contexto, a única conclusão possível é a de se considerar o princípio do non-refoulement como norma de jus cogens, imperativa e consuetudinária, que não pode ser derrogada, a vincular os Estados, ainda no sistema Westfaliano, no trato com os indivíduos em busca de abrigo. Via de consequência, estão aqueles proibidos de violarem a norma, sob qualquer circunstância. Nesse sentido, é uma das maiores garantias de proteção do indivíduo.

\footnotetext{
${ }^{10}$ A exemplo de outras iniciativas a nível mundial, como é o caso da Suíça (PAULA, 2015, p. 63).
} 
Fixada então a premissa segundo a qual as normas que consagram o princípio de non-refoulement têm caráter de normas de jus cogens, a ponto de considerar esse princípio de elevada importância no cenário do direito internacional dos direitos humanos (em particular no que se refere ao direito dos refugiados), impende perscrutar se, em território brasileiro, esse cânone vem sendo ou não devidamente aplicado pelas autoridades da República Federativa do Brasil.

\section{A situação do refúgio no Brasil: tendências}

Os conflitos armados, apesar da hecatombe ocorrida ao longo da Segunda Guerra Mundial e os diversos tratados de direitos humanos que a sucederam, não foram varridos do planeta e ainda explodem em todos os continentes, expondo as populações de várias regiões ao flagelo da guerra, do holocausto e da violação constante dos direitos humanos.

Essa realidade reforça a importância dos direitos dos refugiados como um instrumento de proteção e promoção dos direitos humanos, à medida que, em face da perseguição e do horror, viabiliza o desenvolvimento do ser humano em um outro lugar onde possa viver, constituir ou manter uma família, trabalhar e existir de forma digna e não apenas subsistir enquanto aguarda a própria morte e de seus entes familiares.

O mundo ainda hoje, como ressaltado anteriormente, é delimitado por laços políticos e fronteiras especialmente fiscalizadas e definidas, espaço dentro do qual o ser humano busca realizar a sua experiência existencial, mas onde, muitas vezes, as condições políticas locais sonegam-lhe os mais comezinhos direitos inerentes à espécie humana e inviabilizam o exercício do direito de "pertencer" a uma determinada comunidade ou grupo social, que é o pressuposto fundamental para o gozo de qualquer direito:

O soldado durante a guerra é privado do seu direito à vida; o criminoso, do seu direito à liberdade; todos os cidadãos, numa emergência, do direito de buscarem a felicidade; mas ninguém dirá jamais que em qualquer desses casos houve uma perda de direitos humanos. Por outro lado, esses direitos podem ser concedidos (se não usufruídos) mesmo sob condições de fundamental privação de direitos. A calamidade dos que não têm direitos não decorre do fato de terem sido privados da vida, da liberdade ou da procura da felicidade, nem da igualdade perante a lei ou da liberdade de opinião - fórmulas que se destinavam a resolver problemas dentro de certas comunidades - mas do fato de já não pertencerem a qualquer comunidade (ARENDT, 2012, p. 402).

Atualmente, o conflito na Síria, a título de exemplo, já causou a morte de 230 mil sírios, além de quatro milhões de refugiados (ONU, 2015), sem contar outros focos de tensão na Nigéria, na República Centro-Africana, no Sudão do Sul e na Faixa de Gaza (ONU, 2015).

Na contramão dos conflitos armados espalhados pelo mundo, o Brasil surge como um dos destinados mais procurados pelos refugiados das mais diversas regiões do planeta, possivelmente em função da imagem propagada de um país pluralista, multirracial e receptivo, adicionado ao fato de que, ultimamente, houve uma exposição maior do Brasil na mídia, por conta de eventos globais como a Copa do Mundo de 2014 e as Olimpíadas que realizar-se-ão no ano de 2016.

Dentro desse contexto, houve um exponencial aumento de pedidos de refúgios direcionados ao CONARE - Comitê Nacional para os Refugiados, criado pela Lei $n^{\circ}$ 9.474/1997 e que tem, entre as suas várias atribuições, analisar o pedido e declarar o reconhecimento, em primeira instância, da condição de refugiado (art. 12, inciso I) (BRASIL, 1997).

Se não é possível analisar o mérito de cada uma das decisões tomadas pelas autoridades brasileiras, em especial o CONARE, no que diz respeito à concessão ou ao indeferimento dos pedidos ou solicitações de refúgio, é lícito afirmar que os dados estatísticos disponíveis para pesquisa podem revelar uma determinada postura ou uma determinada tendência na política de refugiados adotada pelo governo brasileiro.

Desde 2010 a população de refugiados vem aumentando no Brasil, passando de 4.357 para $7.289 \mathrm{em}$ 2014, o mesmo podendo ser dito a respeito do número de pedidos de refúgio reconhecido nesse período, que era de apenas 150 em 2010, saltando para $2.032 \mathrm{em}$ 2014 (Acnur, Refúgio no Brasil, 2015).

Houve também um aumento no número de solicitações de refúgio, as quais totalizavam 566 em 2010 , atingindo 8.302 até outubro de 2014; por outro lado, houve um recuo no número das nacionalidades dos novos solicitantes de refúgio, que passaram de 47 no ano de 2010 para 44 em outubro de 2014, tendo havido 67 requerimentos de refúgio no ano de 2013; vale 
registrar que mais da metade desses pedidos de refúgio concentraram-se nas regiões Sul (35\% do total) e Sudeste (31\%) - (Acnur, Refúgio no Brasil, 2015).

Em 2010, os pedidos deferidos alcançavam o percentual de $38,4 \%$ das solicitações e os pleitos indeferidos eram maiores, totalizando $51,7 \%$; entretanto, houve uma inversão nesse cenário, indicando-se que, até outubro de 2014, 88,5\% das solicitações de refúgio haviam sido deferidas pelo CONARE, ao passo que apenas $7,5 \%$ do total de pedidos foram indeferidos (ACNUR, Refúgio no Brasil, 2015), o que revela uma mudança na política do governo brasileiro para refugiados nos últimos quatro anos, muito mais consentânea com o entendimento segundo o qual o princípio do non-refoulement deve ser compreendido como uma norma de jus cogens.

No mês de julho de 2014 o número de refugiados sírios ultrapassou a comunidade colombiana de refugiados no Brasil, tornando-se a principal nacionalidade entre aqueles que pedem refúgio no país e que aqui vivem, embora haja outras nacionalidades que vêm se destacando pelo aumento de pedidos, como Senegal, Gana, Nigéria, os quais, porém, em sua maioria migram por razões econômicas (ACNUR, Dados sobre refúgio no Brasil, 2015).

Segundo a Acnur, "em 2014, a taxa de elegibilidade está em $88,5 \%$, o que pode ser explicado em parte pelo alto índice de deferimento de solicitações de refugiados originários da Síria" (Acnur, Dados sobre refúgio no Brasil, 2015), números que, se fossem excluídos, reduziria a taxa de elegibilidade em 2014 para $75,2 \%$.

Na Declaração de Princípios Internacionais de Proteção dos Refugiados, celebrada em 23 de novembro de 2012, na cidade de Fortaleza, a República Federativa do Brasil, juntamente com os outros países que compõem o MERCOSUL, além de Argentina, Bolívia, Chile, Colômbia, Equador, Peru e Venezuela reafirmaram a proteção, promoção e respeito aos direitos humanos, segundo os valores da solidariedade, da diversidade, do acesso à justiça, da prosperidade, da segurança, da convivência harmônica e da paz, a fim de implementar políticas que promovam e garantam respeito e proteção aos direitos humanos dos refugiados e suas famílias, constituindo-se o "MERCOSUL Ampliado" como um espaço humanitário de proteção dos refugiados (Acnur, Declaração de Princípios, 2015).
Nessa Declaração, os países do "MERCOSUL Ampliado" comprometeram-se com a aplicação do princípio do non-refoulement, estabelecendo-se que os refugiados não serão devolvidos, deportados ou expulsos, não podendo ser encaminhados ao território onde possam ser submetidos a atos de perseguição ou onde suas vidas, liberdade ou integridade física possam estar vulneráveis em razão de raça, religião, nacionalidade, grupo social, opinião política, violência generalizada, agressão estrangeira, conflitos internos, violação massiva de direitos humanos ou outras circunstâncias que perturbem gravemente a ordem pública (Acnur, Declaração de Princípios, 2015).

Ou seja, a partir da assunção do compromisso na Declaração de Princípios Internacionais de Proteção dos Refugiados, nota-se um crescimento do número de pedidos de refúgio deferidos pelas autoridades brasileiras, passando de 22,9\% em 2012 para 88,5\% no ano de 2014 (Acnur, Refúgio no Brasil, 2015), o que nitidamente revela uma mudança de atitude do governo brasileiro em relação à política de refugiados.

Nesse diapasão, considerando-se os compromissos internacionais assumidos pela República Federativa do Brasil, além dos dados extraídos do Alto Comissariado das Nações Unidas para Refugiados, é possível dizer que, nos últimos anos, o Estado brasileiro tem assumido uma posição de destaque, especialmente no que se refere à aplicação do princípio do non-refoulement, que vem sendo interpretado, a julgar pelo aumento dos números de deferimento de solicitações de refúgio, como uma norma imperativa de direito internacional, em face da elevada importância dos direitos dos refugiados para a concretização universal dos direitos humanos.

\section{Cidadania pós nacional: debate}

$\mathrm{Na}$ ordem do quanto exposto neste texto, o princípio do non-refoulement, com a evolução do Direito Internacional dos Direitos Humanos, torna-se norma de jus cogens a limitar e indicar caminhos. Apesar dos avanços, entretanto, ainda existem enormes desafios.

Cumpre salientar que a razão pela qual o Direito Internacional dos Direitos Humanos projeta sua proteção sobre os estrangeiros é por considerá-los um coletivo especialmente vulnerável (MARTÍNEZ, 2012, p. 432). As reflexões modernas a respeito das nossas relações com os que de vêm de fora começam 
com a existência de um mundo de Estados e indivíduos como membros desses Estados. A história do Estado moderno mostra-nos que, no processo de edificação e consolidação do seu poder, a invenção do critério da nacionalidade surge como a estratégia que mais resultados obteve. O mundo ainda hoje é demarcado por laços políticos e fronteiras especialmente fiscalizadas. Rege as relações a ideia de que não se atravessam estas fronteiras sem a devida autorização. Mas mesmo os mais ferrenhos defensores das fronteiras abrem uma exceção para os refugiados. Não importa quão fortes eles considerem as razões para limitar o número ou o tipo de imigrantes que entram no país, eles consideram os refugiados um caso especial (KUKATHAS, 2015, p. 3). Claramente a questão gira em torno de entender o porquê dessa diferenciação - e por que ela não pode ser sustentada.

O problema, em verdade, não é a qualidade da definição em si, mas a busca por uma distinção que dá o tom dessa definição. O objetivo de distinguir entre refugiados, imigrantes, migrantes e afins é limitar e controlar o movimento de pessoas em um mundo em que a liberdade de movimento não é tolerada. Se apenas alguns possuem permissão para se trasladar, a pergunta é sempre: quem? (KUKATHAS, 2015, p. 6). Muitos dizem que a estratégia mais correta seria simplesmente insistir na questão dos refugiados como uma questão humanitária, desnivelando-os dos migrantes econômicos e estabelecendo que são eles pessoas cujos direitos humanos foram violados e precisam ser restaurados. É um argumento que muitos dos que advogam pela causa dos refugiados utilizam, justamente em razão do medo de que se os refugiados forem vistos como migrantes eles seriam reduzidos nos números indesejados de imigrantes rechaçados pelos Estados. Mas esta estratégia só é sustentável se tivermos uma definição que possa de fato ser delineada. Como vimos ao longo deste texto, essa possibilidade parece distante. Ademais, conforme o tempo passa, fica visível que as estruturas institucionais desenhadas tornam mais difíceis para os solicitantes de refúgio levarem adiante suas reivindicações e ganharem efetivamente a proteção que buscam.

E assim, ante os conceitos de cidadania e de nacionalidade tornando-se status de discriminação e exclusão de direitos, faz-se inexorável pensar além.

Immanuel Kant, em “À Paz Perpétua” (KANT, 2008, p. 20), enumera três requisitos/condições a se- rem cumpridos/atingidas para que se logre chegar a um estado de paz mundial. A última delas estabelece o que se chama de "Princípio da Hospitalidade Universal", fundamento do Direito Cosmopolita proposto na obra do filósofo, que seria o coroamento a que a paz perpétua deve conduzir. $O$ respeito a esse princípio implica que cada ser humano goze, em qualquer lugar do mundo, seu status de cidadão.

Essa concepção kantiana da Hospitalidade como o direito que cada indivíduo possui de circular em qualquer lugar do globo sem ser considerado inimigo (FARENA, 2009) é de onde se extrai a ideia de solidariedade entre os povos e vem sendo retomada pelos mais diversos estudiosos sob o manto de que, em maior ou menor grau, os indivíduos possam ser considerados como cidadãos de um grande Estado universal de pessoas, titulares de cidadania universal, cosmopolita ou pós-nacional.

Habermas afirma que o Direito Cosmopolítico é a ideia coerente do desenvolvimento do estado de direito, garantidor dos direitos humanos na sociedade internacional. Ele afirma que a Segunda Guerra Mundial propiciou as condições para a transição do direito internacional ao direito cosmopolita e que a ideia da paz perpétua ganhou força nas instituições, declarações e políticas das Nações Unidas e outras organizações internacionais (FARENA, 2009).

No contexto do desmantelamento gradual do Estado nacional frente às transformações econômicas que ampliavam e tornavam complexas as redes de dependências humanas a partir dos anos 80, Habermas argumenta que só se poderia enfrentar de modo razoável os desafios da globalização se conseguíssemos desenvolver, na sociedade, novas formas de autocondução democrática dentro do que o autor chama de constelação pós-nacional (FERREIRA, 2012, p. 3-4), que é a tendência de uniões políticas entre Estados ante a perda da força do Estado nacional.

O primeiro desafio que a constelação enfrenta é como fazer surgir uma consciência da obrigatoriedade da solidariedade cosmopolita nas sociedades civis e nas esferas políticas dos blocos a se desenvolver. O próprio Habermas responde que a mudança de consciência deve começar com os próprios cidadãos nacionais em termos de política interna, isto é, a transformação do cenário implica uma mudança de consciência a partir da própria população, construindo-se uma constelação em que haja uma multiplicidade de formas de vida, 
contexto em que exsurgiria uma cosmocidadania que, entretanto, não poderia reivindicar uma vida cultural privilegiada:

[...] Puede extraerse como conclusión normativa que los Estados europeos deberían ponerse de acuerdo en una política liberal de inmigración. No deberían atrincheirarse tras la barrera de un "chauvinismo del bienestar" contra la presión de aquellos que quieren inmigrar o que solicitan asilo. El derecho democrático a la autodeterminación incluye, ciertamente, el derecho a preservar la propia cultura política, la cual constituye el contexto concreto para los derechos ciudadanos; pero no incluye el derecho a la autoafirmación de una forma de vida cultural privilegiada. [...] Sólo una ciudadanía democrática que no se cierre en términos particularistas puede, por lo demás, preparar el camino para un status de ciudadano del mundo o una cosmociudadanía, que hoy empieza a cobrar ya forma en comunicaciones políticas que tienen un alcance mundial (HABERMAS, 2010, p. 643).

Essa compreensão de Habermas parece se aproximar do que Giddens (2012, p. 461) chama de multiculturalismo sofisticado, forma que defende a igualdade de status de grupos diferentes, valoriza a diversidade, respeita e interage abertamente com outras culturas, mas que não identifica a igualdade de status com a aceitação da forma acrítica de práticas de outros grupos.

Entretanto, esse modo de encarar o fenômeno dos refugiados, que cada vez mais ganha importância diante do atual fluxo migratório no mundo, especialmente em direção ao território europeu, não está isento de uma crítica mais contundente a um modelo que ainda se agarra aos arquétipos liberais do Estado-nação:

Por su parte, lo que podríamos llamar un liberalismo "intolerante por temeroso", por desgracia muy difundido en Europa y expresado por Sartori, se asusta ante la entrada de inmigrantes con diferentes culturas, convencidos del valor de su cultura (sobre todo musulmanes), y afirma que suponen un peligro para nuestras convicciones occidentales. Ocultando que quienes vienen en las pateras lo hacen urgidos por la miseria, ponen en guardia frente a ellos y frente a su cultura iliberal, recordando que el pluralismo es un valor y aconsejando no tolerar culturas no liberales. Por supuesto, estas advertencias se hacen sólo frente al inmigrante pobre, frente al que los medios de comunicación presentan como un peligro, como fuente supuesta de delincuencia, competencia laboral e intransigência cultural (CORTINA, 2006, p. 7-15).

A construção de um mundo comum, baseado nesse direito de todo ser humano usufruir, onde for, de sua condição de ser humano e cidadão, para Hannah Arendt, que viveu ela própria a condição de refugiada e pessoa sem um país (ARENDT, 1994, pp.110-119), só seria viável se o "direito a ter direitos", peça chave de sua obra como um todo, se convertesse em um tema global (LAFER, 1997), se prevalecesse o direito de todo ser humano à hospitalidade universal. Para a autora, "esta noção de hospitalidade universal significa que as pessoas precisam estar à vontade e em casa no mundo" (FARENA, 2009).

Quando um jovem bósnio, participante de uma discussão a respeito de integração no pós-Acordo de Dayton entre Bósnia e Herzegovina, em Sarajevo, março de 2013, disse: "The renovation of a house does not in itself make a home" desse sentimento de estar "à vontade no mundo" que ele falava.

Nesse contexto, a crise do Estado-nação e a ideia de uma sociedade globalizada, sem fronteiras, pautada pela universalidade dos direitos humanos, permitem afirmar que o próprio conceito de cidadania não mais se atrela à tradição, à origem ou mesmo a um elemento étnico, emergindo uma nova compreensão do instituto, a partir do dever de hospitalidade universal, indispensável para a construção de uma cosmocidadania multicultural e pluralista capaz de concretizar os direitos humanos.

\section{Considerações finais}

A configuração atual do sistema de proteção dos refugiados no mundo surge no pós - Segunda Guerra Mundial, quando o problema dos refugiados toma proporções jamais vistas, culminando na Convenção para o Estatuto dos Refugiados de 1951. Todavia, a limitação do conceito de refugiado expressa neste documento é epicentro, nos dias hodiernos, de uma questão que se apresenta a nível mundial, com o maior número de refugiados desde aquele conflito.

Os números são apenas reflexos de um sistema que há muito não consegue dar conta de resolver os problemas dos refugiados, desafiando as estruturas

\footnotetext{
${ }^{11}$ Tradução livre: "A renovação de uma casa não faz dela um lar".
} 
da governança global, o que implica na necessária revisão de suas bases conceituais.

Como visto ao longo do texto, a evolução do conceito de soberania e a reformulação da própria estrutura do Estado que vemos em andamento nos dias atuais contribuiu para cristalizar o non-refoulement como norma imperativa, que não pode ser derrogada, atendendo aos requisitos necessários para se atingir o status de jus cogens no direito internacional. Via de consequência, os Estados estão impedidos de violarem, individual ou coletivamente, o princípio da não devolução, por qualquer justificativa e em que circunstância for. A natureza de jus cogens do non-refoulement constitui, destarte, uma poderosa arma na proteção dos indivíduos, não só dos que buscam abrigo longe de suas terras, mas principalmente, incluindo-se a possibilidade de responsabilização internacional daqueles que violem a norma.

Apesar dos avanços alcançados, o caminho a ser percorrido na proteção dos refugiados ainda é longo. O problema, em verdade, não é a qualidade da definição de refugiado em si, mas a busca por uma distinção que dá o tom dessa definição.

A construção de um mundo comum, baseado no direito de todo indivíduo de usufruir, onde for, de sua condição de ser humano e cidadão, deve começar não por cada Estado individualmente, mas por cada um de nós, individualmente. Essa é a única condição que nunca se perde e a única que nos faz iguais onde quer que estejamos.

Não devolver alguém que chega à nossa casa pedindo ajuda é sempre o primeiro passo. Mas é inexorável perceber que o conceito de "casa" também deve evoluir. As marginalizações baseadas nos conceitos de nacionalidade e cidadania, que tanto fizeram pelo poder e consequente edificação do Estado moderno, apresentam-se ultrapassadas e insustentáveis. Se o Estado quiser sobreviver, mais uma vez, é hora de se reinventar.

\section{Referências}

ACNUR. ALTO COMISSARIADO DAS NAÇÕES UNIDAS PARA OS REFUGIADOS. Convenção de Genebra relativa ao Estatuto dos Refugiados. Disponível em: $\quad<$ http://www.acnur.org/t3/fileadmin/scripts/doc. php file $=\mathrm{t} 3 /$ fileadmin $/$ Documentos/portugues/BDL/ Convencao_relativa_ao_Estatuto_dos_Refugiados $>$. Acesso em: 08/07/2015.
ACNUR. ALTO COMISSARIADO DAS NAÇÕES UNIDAS PARA REFUGIADOS. Refúgio no Brasil: uma análise estatística (janeiro de 2010 a outubro de 2014). Disponível em: http://www.acnur.org/t3/fileadmin/ Documentos/portugues/Estatisticas/Refugio_no_ Brasil_2010_2014.pdf?view=1. Acesso em: 12/07/2015.

ACNUR. ALTO COMISSARIADO DAS NAÇÕES UNIDAS PARA REFUGIADOS. Dados sobre refúgio no Brasil. Disponível em: http://www.acnur.org/t3/portugues/ recursos/estatisticas/dados-sobre-refugio-no-brasil/. Acesso em: 12/07/2015.

ACNUR. ALTO COMISSARIADO DAS NAÇÕES UNIDAS PARA REFUGIADOS. Declaração de Princípios do Mercosul sobre Proteção Internacional dos Refugiados. Disponível em: http://www.acnur.org/t3/fileadmin/scripts/ doc.php?file $=\mathrm{t} 3 /$ fileadmin/Documentos/portugues $/$ BDL $/$ Declaracao_de_Principios_do_MERCOSUL_sobre Protecao_Internacional_dos_Refugiados. Acesso em: 12/07/2015.

ACNUR. ALTO COMISSARIADO DAS NAÇÕES UNIDAS PARA REFUGIADO. Convenção da Organização de Unidade Africana que rege os Aspectos Específicos dos Problemas dos Refugiados em África. Disponível em: http://www.acnur.org/t3/portugues/recursos/ documentos/. Acesso em: 12/07/2015.

ACNUR. ALTO COMISSARIADO DAS NAÇÕES UNIDAS PARA REFUGIADOS. Declaração de Cartagena de 1984. Disponível em: http://www.acnur.org/t3/portugues/ recursos/documentos/. Acesso em: 12/07/2015.

ARENAS HIDALGO, Nuria de la Cinta, "Mujeres refugiadas: entre el silencio jurídico y la perspectiva de género". In: GALLEGO DURÁN, M.; GARCIA GUTIERREZ, R. (Org.). EI legado plural de las mujeres. Sevilla: Ediciones Alfar, 2005.

ARENDT, Hannah. Origens do totalitarismo: antissemitismo, imperialismo e totalitarismo. Tradução de Roberto Raposo. São Paulo: Companhia das Letras, 2012.

. We refugees. In: Altogether elsewhere, writers on exile. Boston/London: Faber and Faber, 1994.

BIJOS, Leila. Reavaliação do conceito de refugiados. Revista dos Tribunais, São Paulo, v. 943/2014, maio/2014. Disponível em: http://www.revistadostribunais.com.br. Acesso em: 08/07/ 2015.

BRASIL. Decreto n. 7.030, de 14 de dezembro de 2009. Promulga a Convenção de Viena sobre o Direito dos Tratados, concluída em 23 de maio de 1969, com reserva aos Artigos 25 e 66. Disponível em: http://www.planalto. gov.br/ccivil_03/_Ato2007-2010/2009/Decreto/D7030.htm. Acesso em: $23 / 07 / 2015$.

BRASIL. Lei n. 9.474, de 22 de julho de 1997: define mecanismos para a implementação do Estatuto dos 
Refugiados de 1951 e dá outras providências. Disponível em: http://www.planalto.gov.br/Ccivil_03/LEIS/L9474.htm. Acesso em: 08/07/2015.

CAPO, Jasna. "Durable solutions", transnationalism, and homemaking among croatian and bosnian former refugees. Canada's Journal on Refugees, Toronto, v. 31, n. 1. Disponível em: http://refuge.journals.yorku.ca/index.php/ refuge/article/view/40139. Acesso em: 07/07/2015.

CORTINA, Adela. Ciudadanía intercultural. Philosophica, $\mathrm{n}^{\circ}$ 27, p. 7-15, Lisboa, 2006.

FARENA, Maritza Natalia Ferreti Cisneiros. Por uma cidadania universal: os direitos humanos dos migrantes numa perspectiva cosmopolita. Disponível em: http:// www.juragentium.org/topics/migrant/pt/cosmopol.htm\#10. Acesso em: 07/07/2015.

FARMER, Alice. Non-refoulement and jus cogens: limiting anti-terror measures that threaten refugee protection. Georgetown Immigration Journal Law, v. 23, n. 1, fall/2008.

FERREIRA, Hamanda Rafaela Leite. A constelação pósnacional de Habermas e a atual crise europeia. 2012. Disponível em: http://www.abdconst.com.br/revista5/ ferreira.pdf. Acesso em: 07/07/2015.

FOULKES, Imogem. ONU: número de refugiados é o maior desde a Segunda Guerra Mundial. BBC Brasil. 20 de junho de 2014. Disponível em: http://www.bbc.com/portuguese/ noticias/2014/06/140619_refugiados_entrevista_hb. Acesso em: 06/06/2015

GIDDENS, Anthony. Sociologia. Tradução de Ronaldo Cataldo Costa. 6. ed. Porto Alegre: Penso, 2012.

GOODWIN-GILL, Guy. The refugee in international law. NewYork: Oxford University Press, 1998.

GUIMARÃES, André Felipe Figueiredo de Freitas. A evolução do tratamento dos refugiados: um breve estudo acerca dos refugiados angolanos moradores do Rio de Janeiro provenientes da guerra civil angolana. 2014. Disponível em: http://gei.ufrj.br/index.php/2014-07-07-20-19-44/66andreguimaraes. Acesso em: 06/07/2015.

HABERMAS, Jürgen. Facticidad y validez: sobre el derecho y el Estado democrático de derecho en términos de teoría del discurso. Traducción de Manuel Jiménez Redondo. 6. ed. Madri: Editorial Trotta, 2010.

KANT, Immanuel. A Paz Perpétua: um projecto filosófico. Trad. Artur Morão. Covilhã: Universidade da Beira Interior, 2008.

KUKATHAS, Chandran. Are refugees special? Disponível em: https://www.academia.edu/12167749/Are_Refugees Special. Acesso em: 06/06/2015.

KUMIN, J. Género: Persecución cada vez más visible. Revista Refugiados Acnur, n. 111, 2001, p. 12. Disponível em: $\quad$ http://www.acnur.org/t3/fileadmin/scripts/doc. php?file=biblioteca/pdf/0275. Acesso em: 07/07/2015.

LAFER, Celso. A reconstrução dos direitos humanos: a contribuição de Hannah Arendt. Estudos avançados, São Paulo, v. 11 n. 30, mai./ago. 1997. Disponível em: http://www.scielo.br/scielo.php?script=sci_arttext\&pid $=$ S0103-40141997000200005. Acesso em: 07/07/2015.

LAUTERPACHT, Elihu; BETHLEHEM, Daniel. The scope and content of the principle of non-refoulement: opinion. In: FELLER, Erika; TURK, Volker; NICHOLSON, Frances (Eds). Refugee protection in international law. p. 138140. Disponível em: www.unhcr.org/419c75ce4.pdf. Acesso em: 09/07/2015.

LUZ FILHO, José Francisco Sieber. Non-refoulement: breves considerações sobre o limite jurídico à saída compulsória do refugiado. In: ARAÚJO, Nádia de; ALMEIDA, Guilherme Assis de (Coords.). O direito internacional dos refugiados: uma perspectiva brasileira. Rio de Janeiro: Renovar, 2001.

MANDAL, Ruma. Protection Mechanisms Outside of the 1951 Convention ("Complementary Protection"), 2005. Disponível em: http://www.refworld.org/docid/435e198d4. html. Acesso em: 07/07/2015.

MARTÍNEZ, Magdalena María Martín; SÁNCHEZ, Carolina Jimenez. Artículo 19. Protección em caso de devolución, expulsión y extradición. In: ATIENZA, Cristina Monereo; PÉRES, José Luis Monereo. La Europa de los derechos: Estudio sistemático de la carta de los derechos fundamentales de la Unión Europea. Granada: Editorial Comares, 2012.

MOREIRA, Júlia Bertino. A construção e transformação da definição de refugiado. In: Simpósio em relações internacionais do programa de pós graduação em relações internacionais San Tiago Dantas (UNESP, UNICAMP E PUC-SP), I, 2007, Santiago Dantas. São Paulo: UNESP; UNICAMP; PUC-SP, 2007. Disponível em: <http://www. santiagodantassp.locaweb.com.br/br/simp/artigos/moreira2. pdf $>$. Acesso em: 20/07/2015.

NASSER, Salem Hikmat. Jus cogens: ainda esse desconhecido. Revista de Direito Getúlio Vargas, v. 1, n. 2 , p. 161-178, jun.-dez. 2005.

ONU mostra preocupação por crescentes riscos de crianças em conflitos armados. Disponível em: http://noticias. bol.uol.com.br/ultimas-noticias/brasil/2015/06/18/onumostra-preocupacao-por-crescentes-riscos-de-criancas-emconflitos-armados.htm. Acesso em: 13/07/2015.

ONU: número de refugiados sírios ultrapassa 4 milhões. Disponível em: http://agenciabrasil.ebc.com.br/ internacional/noticia/2015-07/onu-numero-de-refugiadossirios-ultrapassa-4-milhoes. Acesso em: 13/07/2015.

PAULA, Bruna Vieira de. O princípio do non-refoulement, sua natureza de jus cogens e a proteção internacional dos 
refugiados. p. 51 - 52. Disponível em: http://www.corteidh. or.cr/tablas/r28151.pdf. Acesso em: 06/06/2015.

PIOVESAN, Flávia. Temas de direitos humanos. 6. ed. São Paulo: Saraiva, 2013.

PROCURADORIA-GERAL DO ESTADO DE SÃO PAULO. Convenção Americana de Direitos Humanos: Pacto de San José da Costa Rica de 1969. Disponível em: http://www.pge.sp.gov.br/centrodeestudos/bibliotecavirtual/ instrumentos/sanjose.htm. Acesso em: 08/07/2015.

ZOLO, Danilo. Do direito internacional ao direito cosmopolita: observações críticas sobre Jürgen Habermas. Política e Trabalho, Revista de Ciências Sociais, n. 22, p. 49-66, João Pessoa, abril de 2005.

Recebido em: 29-07-2015

Aceito em: 07-10-2015 